(RESEARCH ARTICLE)

\title{
Mothers' knowledge about the vaccines their children receive: A study in a Basic Health Unit in the city of Ribeirão Preto, Brazil
}

\author{
Luiz Antonio Del Ciampo ${ }^{1, *}$ Ivan Savioli Ferraz ${ }^{1}$ and Ieda Regina Lopes Del Ciampo ${ }^{2}$ \\ ${ }^{1}$ Department of Puericulture and Pediatrics - Faculty of Medicine of Ribeirão Preto - University of São Paulo - São Paulo \\ - Brazil \\ 2 Department of Medicine - Federal University of São Carlos - São Paulo - Brazil.
}

Publication history: Received on 15 September 2020; revised on 20 November 2020; accepted on 01 December 2020

Article DOI: https://doi.org/10.30574/wjarr.2020.8.3.348

\begin{abstract}
Introduction: vaccines are an important instrument for good health conditions aimed at controlling infectious diseases and reducing childhood morbidity and mortality. Among the various mechanisms to support the practice of vaccination, the knowledge of mothers and caregivers is essential. This article aims to verify the knowledge of mothers about the vaccines that their children receive.

Material and Methods: cross-sectional, observational and descriptive study with mothers of children under five years of age, attended at the childcare and general pediatrics outpatient clinic of a Basic Health Unit (UBS) located in the city of Ribeirão Preto, Brazil, in the period from 01/07/2019 to 12/20/2019. A questionnaire consisting of questions related to social aspects (age, education level, number of children) and vaccines (for which vaccines are used, whether or not you have a vaccine portfolio and illnesses / symptoms of preventable illnesses) was used.

Results: 278 mothers participated, with an average age of 30.5 years. The majority (89.9\%) said that vaccines are used to protect children against infectious diseases and 5.0\% think that vaccines fight disease. 230 mothers (82.7\%) considered vaccines safe, while $46(16.5 \%)$ thought the child was at risk. Regarding the knowledge of diseases that can be prevented by vaccines, 264 (94.9\%) responded affirmatively and cited more frequently measles (56\%), polio (48.4\%), hepatitis (47.7\%) and meningitis (40.1\%).

Conclusions: most of the study participants reported knowing the purpose of vaccines, their safety in clinical practice and the main diseases that can be prevented. This knowledge is essential for children to receive all the vaccines provided for in the immunization programs, contributing to a wide vaccination coverage.
\end{abstract}

Keywords: Vaccines; Immunization; Child Care; Primary Health Care; Health Education

\section{Introduction}

The great smallpox epidemics that have plagued mankind have always prompted laymen, healers, and doctors to try to find ways to prevent the spread of this terrible disease. Although since the 10th century the Chinese have already practiced nasal inoculation of the powder obtained from the scabs of the wounds of sick individuals, it was up to the English doctor Edward Jenner, in 1796, to produce what can be considered the first vaccine against smallpox, obtained from the secretion purulent from the hands of a woman who milked cows and who had contracted the mild form of the disease [1-3]. Since then, the importance of vaccines for the control of infectious diseases has been growing, supported by the eradication of smallpox in the 1980s and the significant reduction in the coefficients of morbidity and mortality from diseases such as polio, whooping cough, tetanus, diphtheria, meningitis, among others. so many others, worldwide, clearly demonstrating the high cost-benefit ratio of these immunobiologicals [4-7].

\footnotetext{
* Corresponding author: Luiz Antonio Del Ciampo

Department of Puericulture and Pediatrics - Faculty of Medicine of Ribeirão Preto - University of São Paulo - São Paulo - Brazil. 
However, all the progress achieved in recent decades has been put at risk due to the so-called "anti-vaccine movements" or "anti-vaccination" that spread around the world since the 1990s, integrated by different segments of society that use arguments such as insecurity regarding the quality of the products, the ineffectiveness of the vaccines and their possible side effects or complications, the interests of the industries that produce immunobiologicals and even due to ignorance about diseases that, thanks to the great vaccine coverage, are no longer verified in many locations [8-13], defending natural alternatives for disease prevention. All these justifications used for not vaccinating children have led to an increase in morbidity and the resurgence of diseases already considered eradicated in some regions of the planet, as in the case of measles $[14,15]$.

Anti-vaccination should be understood as a growing threat to group immunity and the health of populations, since only concerns about the risks to individuals derived from vaccines are being considered, and not the risks due to omission that can lead to greater predisposition to diseases contagious [16,17]. Even though mass vaccination campaigns and programs are widely publicized, they still lack greater understanding and acceptance by the population, which, in many locations, does not respond to the call of health agencies or does not even understand the real need for people to receive multiple doses. vaccines, often using argument without scientific support to stop vaccinating their children [18].

The aim of this study was to verify the knowledge of mothers of children under five years of age about the vaccines that are part of the Ministry of Health Immunization Program, made available by the public service, and the preventable diseases.

\section{Material and methods}

This is a cross-sectional, observational, and descriptive study in which all mothers of children under the age of five, with any health condition, who were attended at the childcare and general pediatric outpatient clinic of a Unit were invited to participate. Basic Health Unit (UBS) located in the western region of the city of Ribeirão Preto, Brazil, from $07 / 01 / 2019$ to $12 / 20 / 2019$. The mothers who agreed to participate were presented with the research objectives, clarified any doubts, and asked to sign a Free and Informed Consent Form. Then, they were asked to answer a questionnaire designed specifically to carry out the study composed of open and closed questions regarding social aspects (age, education level, number of children) and vaccines (what are the vaccines for, whether or not they have vaccines) portfolio of vaccines and diseases signs / symptoms of preventable diseases). Inclusion criteria were adopted: a) mothers of children up to five years old, with any health condition, who seek care at the UBS; b) signing the Informed Consent Form. For mothers under 18 years of age, they were also asked to sign a consent form. Exclusion criteria included incomplete questionnaires and the interviewee's request. The project was submitted for appreciation and approved by the Research Ethics Committee of the School Health Center of the Ribeirão Preto Medical School of the University of São Paulo - protocol 78181616.4.0000.5414. All participants signed the Free Consent Form and the rules of Resolution 466, of 12/12/2012, of the National Health Council for Research involving human beings were observed. The data obtained by the questionnaires were coded, tabulated, and processed in the Microsoft Excel@ program and analyzed statistically in the software Statistical Package for the Social Sciences version 20.0.

\section{Results}

During the second half of 2019, the health unit attended 314 children under 5 years of age and all mothers were invited to participate in the study, of which 278 (88.3\%) agreed. The $36(11.6 \%)$ refusals were justified by lack of interest or time to answer the questionnaire. The average age of the 278 participants was 30.5 years, varying between the youngest with 16 and the oldest with 48 years. All mothers reported having an updated vaccination card when attending the Prenatal program. Table 1 shows some characteristics of these mothers.

When asked about the usefulness of vaccines, the vast majority (89.9\%) said that they are used to protect children against infectious diseases, $5.0 \%$ think that vaccines fight diseases, $2.8 \%$ only answered that they consider that "vaccine it is good for health", while $2.1 \%$ did not know how to answer the purpose of vaccines.

Regarding the possibility of some risk to the child when receiving vaccines $230(82.7 \%)$ answered that they considered the vaccines safe, $46(16.5 \%)$ thought that the child was at some risk and $2(0.7 \%)$ they did not know how to answer. About the knowledge of diseases that can be prevented by vaccines, 264 (94.9\%) answered affirmatively and cited them, as can be seen in Table 2. "Smallpox", "dengue", "anger", "Herpes" and "human papillomavirus infection" were also remembered. 
Table 1 Distribution of social characteristics of 278 mothers interviewed - Ribeirão Preto 2019

\begin{tabular}{|l|l|l|}
\hline & $\mathbf{n}$ & $\mathbf{\%}$ \\
\hline Age (years) & & \\
\hline$<20$ & 16 & 5,7 \\
\hline $20-29$ & 98 & 35,2 \\
\hline $30-39$ & 142 & 51,1 \\
\hline$\geq 40$ & 22 & 7,9 \\
\hline Schooling & & \\
\hline 1 o degree & 12 & 4,3 \\
\hline 2 o degree & 82 & 29,4 \\
\hline High school & 120 & 43,1 \\
\hline University education & 64 & 23,1 \\
\hline Number of children & & \\
\hline 1 & 128 & 46,0 \\
\hline 2 & 96 & 34,5 \\
\hline 3 or more & 54 & 19,5 \\
\hline
\end{tabular}

Table 2 Distribution of vaccine-preventable diseases cited by mothers - Ribeirão Preto 2019

\begin{tabular}{|l|l|l|}
\hline Disease & n & \% \\
\hline measles & 148 & 56,0 \\
\hline poliomielytis & 128 & 48,4 \\
\hline hepatitis & 126 & 47,7 \\
\hline meningitis & 106 & 40,1 \\
\hline yellow fever & 96 & 36,3 \\
\hline flu & 96 & 36,3 \\
\hline rubella & 88 & 33,3 \\
\hline mumps & 74 & 28,0 \\
\hline tetanus & 66 & 25,0 \\
\hline varicella & 48 & 18,1 \\
\hline whooping cough & 46 & 17,4 \\
\hline tuberculosis & 46 & 17,4 \\
\hline pneumonia & 28 & 10,6 \\
\hline diphtheria & 20 & 7,5 \\
\hline diarrhea & 18 & 6,8 \\
\hline
\end{tabular}

Regarding the knowledge of specific signs or symptoms of the most common vaccine-preventable diseases, 206 (74.1\%) mothers offered correct answers, which are shown in table 3. 
Table 3 Distribution of diseases known to mothers who had correctly referred signs and / or symptoms - Ribeirão Preto 2019.

\begin{tabular}{|l|l|l|}
\hline Disease & $\mathbf{n}$ & $\mathbf{\%}$ \\
\hline mumps & 158 & 76,7 \\
\hline pneumonia & 142 & 68,9 \\
\hline tuberculosis & 123 & 65,0 \\
\hline measles & 118 & 57,2 \\
\hline hepatitis & 101 & 49,0 \\
\hline meningitis & 98 & 47,5 \\
\hline poliomielytis & 64 & 33,0 \\
\hline rubella & 52 & 25,2 \\
\hline Yellow fever & 42 & 20,3 \\
\hline Whooping cough & 38 & 18,4 \\
\hline tetanus & 16 & 7,7 \\
\hline diphtheria & 8 & 3,8 \\
\hline
\end{tabular}

\section{Discussion}

The knowledge, attitudes, and beliefs of mothers about vaccines are fundamental elements that must be considered when proposing to improve the rates of vaccination coverage in the child population $[19,20]$. For children under five years of age, both the Ministry of Health, through its National Immunization Program, and the World Health Organization indicate that vaccines against tuberculosis, hepatitis B, diphtheria, tetanus, whooping cough, polio, hepatitis A, chickenpox, yellow fever, measles, mumps, rubella, rotavirus, meningitis and diseases caused by pneumococcus, influenza viruses and Haemophilus infuenzae [2-123).

In view of the large number of vaccines to be applied, the many unsubstantiated information that come to the knowledge of the community and the lack of health education for a large part of the population, it is possible to understand, at least partially, the reasons that lead to vaccination refusal. In this sense, it is important to identify what is the mothers' knowledge about the role of vaccines for the child's health.

In the same way that the present study observed positive evaluations of the benefits that vaccines can provide to children, such findings have also been verified by other authors when interviewing mothers who used outpatient services in the city of Rio de Janeiro [24,25], in units of family health in Natal [26], in basic health units in Bauru [27,28], Fortaleza [1] and Jaboatão dos Guararapes [29] which combine vaccines with protection against infectious diseases and health benefits. In all studies, the responses were that vaccines prevent disease.

Social, economic, and cultural differences directly influence the way people receive information about health care and transform it into effective actions. The low educational level reflects directly on health conditions, as much information regarding the benefits of vaccines may not be properly understood [30,31]. In the present study, 66.2\% of mothers have a medium or higher educational level, which increases their ability to understand the guidelines offered in relation to vaccines during childcare visits. But the reality is variable, as seen in other communities in which the results showed that $69.8 \%$ of mothers did not know why the children were being vaccinated, nor the vaccines they had received $[26,31,32]$.

Knowledge about vaccine-preventable diseases, with their regional variations, is related to vaccine coverage. In the present study, the most well-known diseases were measles (56\%), polio (48.4\%), hepatitis (47.7\%) and meningitis (40.1\%), similarly to what was verified in a research carried out in a basic unit in Pernambuco [29] in which the results found references to polio, measles, hepatitis, and meningitis. Other authors were also able to identify more references to hepatitis, polio, yellow fever, and tuberculosis [31] in the interior of the state of Piaui. Studies carried out in Fortaleza 
and Belo Horizonte pointed out yellow fever, poliomielitys and tetanus as the most well-known diseases among laypeople [26,33].

\section{Conclusion}

One of the most important contributions to the wide vaccination coverage is given by the Childcare Programs, whose objectives include protection against infectious diseases also through vaccination. However, it can still be seen that even these Primary Health Care Programs for Children are not available or do not reach a large part of the population, in addition to being relegated to secondary plans, failing to exercise their fundamental role related to disease prevention and promotion child health [34].

Frequent contact with health teams, presence in basic units and the dissemination of beneficial aspects of vaccination must be prioritized for all families, especially those that have members, children, and adolescents [35,36]. For the lay population, the main source of information is still the media [37-40] and it should be used responsibly to educate about the benefits of vaccines and discourage anti-vaccination movements [41-43].

Doctors and other health professionals, in addition to managers, play a fundamental role in helping family members make decisions about vaccines [44-46]. It is important to recognize and identify the concerns of caregivers / patients, through research and social and psychological studies, to establish strategies to reverse the situations. Public health agents, social organizations, schools, etc. should be involved [41,42]. The study has some limitations regarding the small number of participating mothers and attending the health unit where information about the importance of vaccines is offered. However, it has the merit of seeking to maintain the discussion about the need to maintain the proper vaccination schedule and to avoid the dissemination of erroneous information about the importance of vaccines.

\section{Compliance with ethical standards}

\section{Disclosure of conflict of interest}

All authors declare that they have no conflict of interest.

\section{Statement of informed consent}

Informed consent was obtained from all individual participants included in the study.

\section{References}

[1] Sousa ZM, Santos A, Albuquerque VLM, Sampaio FHS. Vaccination - what does the user know? Rev Bras Pesq Saúde 2005; 18:24-30.

[2] McClure CC, Cataldi JR, O'Leary ST. Vaccine hesitancy: where we are and where we are going? Clin Ther 2017; 39:1550-1558.

[3] Andreano E, D'Oro U, Rappuoli R, Finco O. Vaccine evolution and its application to fight modern threats. Front Immunol 2019; 10:1722-1729.

[4] Ozawa S, Stack ML, Bishai DM, Mirelman A, Friberg IK, Niessen L et al. During the 'Decade Of Vaccines,' the lives of 6.4 million children valued at $\$ 231$ billion could be saved. Health Aff 2011; 30:1010-1020.

[5] Hussain A, Ali S, Ahmed M, Hussain S. The anti-vaccination movement: the regression in modern medicine. Cureus 2018; 10:e2919-e2926.

[6] Maurice A, Edwards KM, Hackell J. Addressing vacinne hesitancy in clinical practice. Pediatr Ann 2018; 47:e366e370.

[7] Facciolà A, Visalli G, Orlando A, Bertuccio MA, Spataro P, Squeri R et al. Vaccine hesitancy: an overview on parents' opinions about vaccination and possible reasons of vaccine refusal. J Pub Health Res 2019; 8:1346-1440.

[8] Leask J. Should we do battle with antivaccination activists? Pub Health Res Pract 2015; 25:e2521-e2525.

[9] Horne Z, Powell D, Hummel JE, Holyoak KJ. Countering antivaccination atitudes. Proc Natl Acad Sci 2015; 112:10321-10324. 
[10] Blaisdell LL, Gutheil C, Hootsmans NAM, Han PKJ. Unknown risks: parental hesitation about vaccination. Med Decis Making. 2016; 36:479-489.

[11] Smith TC. Vaccine rejection and hesitancy: a review and call to action. Open Forum Infect Dis 2017; 4:1-6.

[12] Wilson R, Paterson P, Larson HJ. Strategies to improve maternal vaccination acceptance. Public Health 2019; 19:342-350.

[13] Chang K, Lee SY. Why do some Korean parents hesitate to vaccinate their children? Epidemiol Health 2019; 41:17.

[14] Gowda C, Dempsey AF. The rise (and fall?) of parental vaccine hesitancy. Hum Vac Immunother 2013; 9:17551762.

[15] Conis E. Measles and the modern history of vaccination. Pub Health Rep 2019; 134:118-125.

[16] Piqueras MC, Cortazar ARG, Carmona JH, Bernáldez JP. Reticencia vacunal: análisis del discurso de madres y padres con rechazo total/parcial a las vacunas. Gac Sanit 2019; 33:53-59.

[17] Navin MC, Wassermann JA, Ahmad M, Bies S. Vaccine education, reasons for refusal, and vaccination behavior. Am J Prev Med 2019; 56:359-367

[18] Sato APS. What is the importance of vaccine hesitancy in the drop of vaccination coverage in Brazil? Rev Saúde Publica 2018; 52:96-104.

[19] Williams AL, Mitrocich R, Mwananyanda L, Gill C. Maternal vaccine knowledge in low- and middle income countries - and why it matters. Huma Vac Immun 2019; 15:283-286.

[20] Dubé E, Farrands A, Lemaitre T, Boulianne N, Sauvageau C, Boucher FD et al. Overview of knowledge, attitudes, beliefs, vaccine hesitancy and vaccine acceptance among mothers of infants in Quebec, Canada. Hum Vaccin Immunother 2019; 15:113-120.

[21] WHO. Global Vaccine Action Plane. 2011-2020. Geneva. 77 p. 2013.

[22] Brasil. Ministério da Saúde. http://www.saude.gov.br/saude-de-a-z/vacinacao/calendario-vacinacao.

[23] Couto MT, Barbieri CLA. Care and (non)-vaccination in the context of high-income and well-schooled families in São Paulo in the state of São Paulo, Brazil. Ciênc Saúde Coletiva 2015; 20:105-112.

[24] Pugliesi MV, Tura LFR, Andreazzi MFS. Mothers and the vaccination of children: a study of social representation in the public health sector. Rev Bras Saude Matern Infant 2010; 10:75-84.

[25] Ballali I. Anti-vaccination in Brazil: how are we doing and what can we do? Rev Ped SOPERJ 2019; 19:1-2.

[26] Oliveira VG, Pedrosa KKA, Monteiro AI, Santos ADB. Vaccination: the nursing do and the mother and/or caretaker's knowledge. Rev Rene 2010; 11:133-141.

[27] Gatti MAN, Oliveira LR. Crianças faltosas à vacinação, condições de vida da família e concepção sobre vacina: um inquérito domiciliar. Salustiva 2005; 24:427-436.

[28] Sousa CJ, Vigo ZL, Palmeira CS. Parent's comprehension about the importance of childhood vaccination. Rev Enf Contemp 2012; 1:44-58.

[29] Cordeiro EL, Silva LSR, Urquiza JL, Nascimento MA, Silva RM, Souza GCS et al. Knowledge of mothers on the vaccine scheme of their children assisted in a basic health unit. Braz J Hea Rev 2019; 2:644-660.

[30] Santos LB, Barreto CCM, Silva FLS, Silva KCO. Perception of mothers regarding the importance of child immunization. Rev Rene 2011; 12:621-626.

[31] Carvalho IVRL, Oliveira EAR, Lima LHO, Formiga LMF, Silva AKA, Rocha SS. Knowledge of mothers regarding vaccines administered in the first year of life. Rev Bras Ciênc Saúde 2015; 19:205-210.

[32] Molina AC, Godoy I, Carvalho LR, Caldas Junior AL. Situação vacinal infantil e características individuais e familiares do interior de São Paulo. Acta Sci Health Sci 2007; 29:99-106.

[33] Viegas SMF, Sampaio FC, Oliveira PP, Lanza FM, Oliveira VC, Santos WJ. Vaccination and adolescent knowledge: health education and disease prevention. Cien Saude Colet 2019; 24:351-360.

[34] Góes FGB, Silva MA, Paula GK, Oliveira LPM, Mello MC, Silveira SSD. Nurses' contributions to good practices in child care: an integrative literature review. Rev Bras Enferm 2018; 71(suppl 6):2974-2983. 
[35] Andrade DRS, Lorenzini E, Silva EF. Mother's knowledge regarding the vaccination program and factors which lead to delays in infant vaccination. Cogitare Enf 2014; 19:96-102.

[36] Bryden GM, Browne M, Rockloff M, Unsworth C. The privilege paradox: geographic areas with highest socioeconomic advantage have the lowest rates of vaccination. Vaccine 2019; 37:4525-4532.

[37] Osis MJD, Duarte GA, Souza MH. SUS users' knowledge of and attitude to HPV virus and vaccines available in Brazil. Rev Saúde Pública 2014; 48:123-133.

[38] Aggarwal A. Childhood vaccine refusal and hesitancy - reasons. Ind J Pediatr 2019; 86:5-6.

[39] Tafuri S, Gallone MS, Gallone MF, Zorico I, Aiello V, Germinario C. Communication about vaccinations in Italian websites. Hum Vac Immnunother 2014; 10:1416-1420.

[40] Nayar RK, Nair AT, Shaffi M, Swarnam K, Kumar A, Abraham M et al. Methods to overcome vaccine hesitancy. Lancet 2019; 393-1203-1204.

[41] Vyas D, Galal SM, Rogan EL, Boyce EG. Training students do address vaccine hesitancy and/or refusal. Am J Pharm Educ 2018; 82:944-953

[42] Hurst DJ. Strategy to address vaccine refusal must include research, training, and advocacy. Fam Med 2019; 9:787.

[43] Omer SB, Salmon DA, Orestein WA, deHart P, Halsey N. Vaccine refusal, mandatory immunization, and the risks of vaccine-preventable diseases. N Eng J Med 2009; 360:1981-1988.

[44] Di Pietro ML, Poscia A, Teleman AA, Maged D, Ricciardi W. Vaccine hesitancy: parental, professional, and public responsability. Ann Ist Super Sanità 2017; 53:157-162.

[45] Succi RCM. Vaccine refusal - what we need to know? J Pediatr (Rio J) 2018; 94:574-581.

[46] MacDonald NE, Butler R, Dubè E. Addressing barriers to vaccine acceptance: an overview. Hum Vac Immunother 2018; 14:218-224. 